\author{
Andrzej FRAC CKOWIAK ${ }^{1}$ \\ Michał CIAŁKOWSKI ${ }^{2}$ \\ Agnieszka WRÓBLEWSKA ${ }^{3}$
}

\title{
ALGORYTM ITERACYJNEGO ROZWIĄZYWANIA ZAGADNIEŃ ODWROTNYCH PRZEWODNICTWA CIEPŁA Z MINIMALIZACJA OSCYLACJI TEMPERATURY
}

\begin{abstract}
W pracy rozwiązane zostało zagadnienie odwrotne dla przypadku stacjonarnego pola temperatury w obszarze wielospójnym, które jest ważne $\mathrm{z}$ technicznego punktu widzenia i dotyczy problemu chłodzenia łopatek turbin gazowych. Rozwiązane zostało zagadnienie odwrotne testowe dla obszaru pierścienia eliptycznego, w którym znany jest rozkład temperatury oraz współczynnik przejmowania ciepła na brzegu zewnętrznym obszaru. Na tej podstawie wyznaczony został rozkład temperatury oraz gęstości strumienia ciepła na brzegu wewnętrznym pierścienia. W funkcjonale optymalizującym rozwiązanie zagadnienia odwrotnego uwzględniony został człon związany z gradientem temperatury w całym obszarze. Obliczenia przeprowadzono dla znanego rozkładu współczynnika przejmowania ciepła na brzegu zewnętrznym obszaru zaburzonego błędem losowym równym 0 , 1,5 oraz $10 \%$. Zbadano wpływ gradientu temperatury na czas i dokładność obliczeń. Uwzględnienie gradientu temperatury w funkcjonale, który jest minimalizowany w procesie obliczeniowym skróciło czas obliczeń oraz zmniejszyło oscylacje rozkładu temperatury oraz strumienia ciepła na brzegu wewnętrznym obszaru wielospójnego.
\end{abstract}

Słowa kluczowe: turbiny gazowe, zagadnienia odwrotne, zagadnienie Cauchy'ego

\section{Wprowadzenie}

Zagadnienia odwrotne należą dla klasy zagadnień źle postawionych w sensie Hadamarda [5]. Istnieje wiele algorytmów rozwiązywania takich zagadnień, z których najważniejsze to regularyzacjaTikhonova $[1,8]$, algorytm svd (singular value decomposition) [7] oraz algorytmy iteracyjne [2]. Zagadnienie od-

\footnotetext{
${ }^{1}$ Autor do korespondencji/corresponding author: Andrzej Frąckowiak, Politechnika Poznańska, pl. Marii Skłodowskiej-Curie 5, 60-965 Poznań, 61665 2779, andrzej.frackowiak@ poznan.pl.

${ }^{2}$ Michał Ciałkowski, Politechnika Poznańska, michal.cialkowski@ poznan.pl.

${ }^{3}$ Agnieszka Wróblewska, Politechnika Poznańska, agnieszka.wroblewska@poznan.pl.
} 
wrotne, które zostało rozwiązane w pracy jest ważne z technicznego punktu widzenia i dotyczy problemu chłodzenia łopatek turbin gazowych. Profil łopatki z kanałami chłodzącymi rozmieszczonymi w jej wnętrzu jest przykładem obszaru wielospójnego o skomplikowanej strukturze. W zagadnieniach projektowych zadany jest rozkład temperatury i współczynnik przejmowania ciepła na brzegu zewnętrznym $\alpha$, należy wyznaczyć rozkład temperatury oraz strumienia ciepła na ścianach kanałów chłodzących (zagadnienie Cauchy’ego).

W pracy [4] poszukiwano rozkładów temperatury i strumienia ciepła w kanałach chłodzących łopatki dla stałej wartości temperatury na jej brzegu zewnętrznym $\Gamma_{z}$, rys.1. Funkcjonał, którego minimum poszukiwane jest w procesie optymalizacji ma następującą postać:

$$
J=\frac{1}{2} \int_{\Gamma_{z}}\left(T-T_{o}\right)^{2} d s
$$

gdzie $T_{o}$ - zadana temperatura na brzegu zewnętrznym.

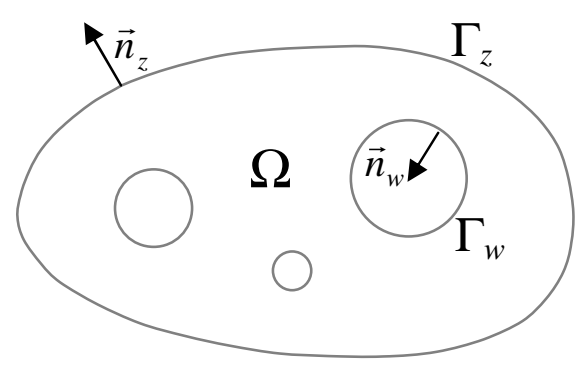

Rys. 1. Obszar wielospójny $\Omega$ ograniczony brzegiem $\Gamma=\Gamma_{z} \cup \Gamma_{w}$

Fig. 1. Multiply-connected domain $\Omega$ bounded by the boundary $\Gamma=\Gamma_{z} \cup \Gamma_{w}$

Obliczenia prezentowane w pracy [4] dotyczyły łopatki C3X z dziesięcioma kanałami chłodzącymi o przekroju kołowym [6]. Rozkład temperatury na brzegu zewnętrznym łopatki silnie oscylował na tych częściach brzegu łopatki, które znajdowały się w pobliżu kanałów chłodzących. Powodowało to silne oscylacje temperatury oraz strumienia ciepła na ścianach kanałów chłodzących łopatki. Tak otrzymane rozwiązanie odwrotne musiało być w każdym kanale uśrednione. $\mathrm{Z}$ przeprowadzonych badań wynika potrzeba modyfikacji funkcjonału (1) oraz zbadania wpływu błędu losowego warunków brzegowych na stabilność rozwiązania zagadnienia odwrotnego ze zmienionym funkcjonałem. Badania takie dla funkcjonału postaci (1) przedstawiono w pracy [3]. Efekt oscylacji rozwiązania zagadnienia odwrotnego z pracy [4] może zostać stłumio- 
ny przez zastosowanie następującego funkcjonału, zdefiniowanego dla obszaru wielospójnego, rys. 1:

$$
J=\frac{1}{2} \int_{\Gamma_{z}}\left(T-T_{o}\right)^{2} d s+\frac{\gamma}{2} \int_{\Omega}(\nabla T)^{2} d \omega, \quad \gamma>0
$$

gdzie $T_{\boldsymbol{o}}$ - zadana temperatura na brzegu zewnętrznym.

Oscylacje temperatury mają wpływ na wartość funkcjonału (2). Minimalizacja funkcjonału (2) powoduje, że funkcja temperatury $T$ będzie w procesie iteracji wygładzana. W niniejszej pracy założono ponadto, że na brzegu zewnętrznym obszaru $\Gamma_{z}$ zadana jest temperatura (warunek brzegowy I rodzaju) oraz współczynnik przejmowania ciepła $\alpha$ (warunek brzegowy III rodzaju). Jest to zagadnienie Cauchy'ego dla równania Laplace'a.

\section{Algorytm iteracyjny}

Zagadnienie Cauchy'ego dla równania Laplace'a w obszarze wielospójnym (rys. 1) sprowadza się do rozwiązania równania Laplace'a w obszarze $\Omega$

$$
\Delta T=0
$$

$\mathrm{z}$ warunkiem brzegowym III rodzaju na brzegu $\Gamma_{z}$ :

$$
-\lambda \partial_{n} T=\alpha\left(T-T_{p}\right)
$$

( $\partial_{n}$ - operator pochodnej normalnej, $T_{p}$ - temperatura płynu otaczającego brzeg zewnętrzny obszaru $\Omega, \alpha$ - współczynnik przejmowania ciepła, $\lambda$ - współczynnik przewodzenia ciepła) i funkcjonałem (2).

Rozwiązywanie tak postawionego zagadnienia odwrotnego może zostać zastąpione rozwiązywaniem kolejnych zagadnień bezpośrednich:

$$
\begin{array}{ll}
\Omega: & \Delta T=0 \\
\Gamma_{z}: & -\lambda \partial_{n} T=\alpha\left(T-T_{p}\right) \\
\Gamma_{w}: & \partial_{n} T=g
\end{array}
$$

Funkcja $g$ określona na brzegu $\Gamma_{w}$ obszaru $\Omega$ zmienia się iteracyjnie tak, aby funkcjonał (2) w granicy procesu iteracyjnego osiągną minimum. W tym celu należy wyznaczyć wariację $\delta J$ tego funkcjonału. Wariacja funkcjonału (2) jest równa: 


$$
\delta J[g]=\int_{\Gamma_{z}}\left(T(g)-T_{o}\right) \delta T(g) d s+\gamma \int_{\Omega} \nabla T(g) \nabla \delta T(g) d \omega
$$

Korzystając ze związku:

$$
\int_{\Omega} \nabla T \nabla \delta T d \omega=\int_{\Gamma_{z}} \partial_{n} T \delta T d s+\int_{\Gamma_{w}} \partial_{n} T \delta T d s
$$

oraz uwzględniając warunki brzegowe (5) dla funkcji $T$ i warunki brzegowe dla funkcji $\delta T$

$$
\begin{array}{ll}
\Gamma_{z}: & \partial_{n}(\delta T)=-\frac{\alpha}{\lambda} \delta T \\
\Gamma_{w}: & \partial_{n}(\delta T)=\delta g
\end{array}
$$

otrzymujemy

$$
\int_{\Omega} \nabla T(g) \nabla \delta T(g) d \omega=-\int_{\Gamma_{z}} \frac{\alpha}{\lambda} T(g) \delta T(g) d s+\int_{\Gamma_{w}} T(g) \delta g d s
$$

Ostatecznie wariacja funkcjonału (2) ma postać:

$$
\delta J[g]=\int_{\Gamma_{z}}\left[\left(1-\frac{\gamma \alpha}{\lambda}\right) T(g)-T_{o}\right] \delta T(g) d s+\gamma \int_{\Gamma_{w}} T(g) \delta g d s
$$

Aby wyznaczyć występującą we wzorze (8) wariację $\delta T$ funkcji $T$ na brzegu $\Gamma_{z}$ potrzebna jest pomocnicza funkcja $p$ (sprzężona $\mathrm{z} \delta T$ ), spełniająca równanie Laplace'a. Dla funkcji $\delta T$ oraz $p$ prawdziwa jest tożsamość:

$$
\begin{aligned}
& \int_{\Gamma_{z}} \partial_{n}(\delta T) p d s+\int_{\Gamma_{w}} \partial_{n}(\delta T) p d s=\int_{\Gamma_{z}} \delta T \partial_{n} p d s+\int_{\Gamma_{w}} \delta T \partial_{n} p d s \\
& \int_{\Gamma_{z}}\left(\partial_{n} p+\frac{\alpha}{\lambda} p\right) \delta T d s=\int_{\Gamma_{w}} \delta g p d s-\int_{\Gamma_{w}} \delta T \partial_{n} p d s
\end{aligned}
$$

Funkcję $p$ można zdefiniować dowolnie. Jeśli funkcja $p$ jest określona jako: 


$$
\begin{aligned}
& \Omega: \quad \Delta p=0 \\
& \Gamma_{z}: \quad \partial_{n} p=-\frac{\alpha}{\lambda} p+\left(1-\frac{\gamma \alpha}{\lambda}\right) T-T_{o} \\
& \Gamma_{z}: \quad \partial_{n} p=0
\end{aligned}
$$

to wstawiając tak zdefiniowaną funkcję do wzoru (8), otrzymujemy:

$$
\int_{\Gamma_{z}}\left[\left(1-\frac{\gamma \alpha}{\lambda}\right) T+T_{o}\right] \delta T d s=\int_{\Gamma_{w}} p \delta g d s
$$

Zatem wariacja funkcjonału (2) wynosi:

$$
\delta J[g]=\int_{\Gamma_{w}}(p+\gamma T) \delta g d s
$$

Wariacja funkcjonału $J[g]$ w otoczeniu minimum funkcjonału powinna być mniejsza od zera. Przyjmując:

$$
\delta g=-\eta(p+\gamma T), \quad \eta>0
$$

otrzymujemy:

$$
\delta J[g]=-\eta \int_{\Gamma_{w}}(p+\gamma T)^{2} d s<0
$$

Powyższe rozumowanie posłuży do konstrukcji algorytmu iteracyjnego. Zakładając, że funkcje $T$ oraz $g$ zmieniają się iteracyjnie wg wzorów:

$$
\begin{aligned}
& \Omega: \quad T^{m+1}=T^{m}-\eta u^{m} \\
& \Gamma_{w}: \quad g^{m+1}=g^{m}-\eta\left(p^{m}+\gamma T^{m}\right)
\end{aligned}
$$

oraz znając wartości funkcji $T \mathrm{w} m$-tym kroku iteracji, można wyznaczyć funkcje $p^{m}, u^{m}$, spełniające równanie Laplace' a $\mathrm{z}$ warunkami brzegowymi:

- dla funkcji $p^{m} \mathrm{z}$ warunkami brzegowymi (10),

- dla funkcji $u^{m}$ : 


$$
\begin{aligned}
& \Gamma_{z}: \quad \partial_{n} u^{m}=-\frac{1}{\eta}\left(\partial_{n} T^{m+1}-\partial_{n} T^{m}\right)=\frac{\alpha}{\eta \lambda}\left(T^{m+1}-T^{m}\right)=-\frac{\alpha}{\lambda} u^{m} \\
& \Gamma_{w}: \quad \partial_{n} u^{m}=-\frac{1}{\eta}\left(g^{m+1}-g^{m}\right)=\left(p^{m}+\gamma T^{m}\right)
\end{aligned}
$$

Do wyznaczenia funkcji $T$ oraz $g$ w kolejnym kroku iteracji należy obliczyć wartość parametru $\eta$. Z warunku

$$
J\left[g^{m+1}\right]<J\left[g^{m}\right]
$$

otrzymujemy

$$
\begin{aligned}
& J\left[g^{m+1}\right]-J\left[g^{m}\right]= \frac{1}{2} \int_{\Gamma_{z}}\left[\left(T^{m+1}-T_{o}\right)^{2}-\left(T^{m}-T_{o}\right)^{2}\right] d s \\
&+\frac{\gamma}{2} \int_{\Omega}\left(\nabla\left(T^{m+1}\right)-\nabla\left(T^{m}\right)\right)^{2} d \omega \\
& J\left[g^{m+1}\right]-J\left[g^{m}\right]=-\eta\left[\int_{\Gamma_{z}}\left(T^{m}-T_{o}\right) u^{m} d s+\gamma \int_{\Omega} \nabla T^{m} \nabla u^{m} d \omega\right] \\
&+\frac{\eta^{2}}{2}\left[\int_{\Gamma_{z}}\left(u^{m}\right)^{2} d s+\gamma \int_{\Omega}\left(\nabla u^{m}\right)^{2} d \omega\right]<0
\end{aligned}
$$

Ze wzorów (6), (12) wynika, że

$$
\int_{\Gamma_{z}}\left(T^{m}-T_{o}\right) u^{m} d s+\gamma \int_{\Omega} \nabla T^{m} \nabla u^{m} d \omega=\int_{\Gamma_{w}}\left(p^{m}+\gamma T^{m}\right)^{2} d s
$$

zatem optymalna wartość $\eta$ wyraża się wzorem:

$$
\eta_{\text {opt }}=\frac{\int_{\Gamma_{w}}\left(p^{m}+\gamma T^{m}\right)^{2} d s}{\int_{\Gamma_{z}}\left(u^{m}\right)^{2} d s+\gamma \int_{\Omega}\left(\nabla u^{m}\right)^{2} d \omega}
$$

Ostatecznie algorytm iteracyjny jest postaci 
krok 1: $\quad \Omega: \Delta T^{0}=0$

$$
\begin{array}{ll}
\Gamma_{z}: & \partial_{n} T^{0}=-\frac{\alpha}{\lambda}\left(T^{0}-T_{p}\right) \\
\Gamma_{w}: & \partial_{n} T^{0}=0
\end{array}
$$

krok 2: $\Omega: \Delta p^{m}=0$

$$
\begin{aligned}
& \Gamma_{z}: \quad \partial_{n} p^{m}=-\frac{\alpha}{\lambda} p^{m}+\left(1-\frac{\gamma \alpha}{\lambda}\right) T^{m}-T_{o} \\
& \Gamma_{w}: \quad \partial_{n} p^{m}=0
\end{aligned}
$$

krok 3: $\Omega: \Delta u^{m}=0$

$$
\begin{array}{ll}
\Gamma_{z}: & \partial_{n} u^{m}=-\frac{\alpha}{\lambda} u^{m} \\
\Gamma_{w}: & \partial_{n} u^{m}=\left(\begin{array}{l}
\left.p^{m}+\gamma T^{m}\right)
\end{array}\right.
\end{array}
$$

krok 4:

$$
\eta=\frac{\int_{\Gamma_{w}}\left(p^{m}+\gamma T^{m}\right)^{2} d s}{\int_{\substack{\Gamma_{z} \\ \Gamma^{m+1}}}\left(u^{m}\right)^{2} d s+\gamma \int_{\Omega}\left(\nabla u^{m}\right)^{2} d \omega}
$$

krok 5: jeśli $a b s\left(T^{m+1}-T^{m}\right)>$ eps to $m=m+1$ idź do krok 2:

\section{Przykład numeryczny}

Poniżej rozpatrzono zagadnienie odwrotne stacjonarnego przewodnictwa ciepła w obszarze wielospójnym $\Omega$, rys. 2 (zagadnienie Cauchy’ego), którego brzegi są dane wzorami, [3]:

$$
\begin{aligned}
& \Gamma_{z}: \quad x^{2}+\frac{y^{2}}{0,7^{2}}=1 \\
& \Gamma_{w}: \quad \frac{(x-0.1)^{2}}{0,6^{2}}+\frac{y^{2}}{0,4^{2}}=1
\end{aligned}
$$

Rozkład temperatury i strumienia ciepła na brzegu zewnętrznym pierścienia wyznaczono ze wzoru:

$$
T_{a}(r, \varphi)=0,7-0,1 \cdot \ln \left|z-z_{1}\right|+0,2 \cdot \ln \left|z-z_{2}\right|
$$


gdzie $z$ jest zmienną zespoloną, $z=r \cdot e^{i \varphi}, z_{1}=1,2 \cdot e^{i \frac{3 \pi}{4}}$, a $z_{2}=0,3 \cdot e^{-i \frac{\pi}{2}}$.

Współczynnik przejmowania ciepła $\alpha$ na brzegu zewnętrznym został zaburzony błędem losowym o odchyleniu standardowym $\delta=0 ; 1 ; 5$ oraz $10 \%$. To zagadnienie odwrotne rozwiązane zostało metodą elementów skończonych $\mathrm{w}$ programie FreeFem++ dla parametru algorytmu iteracyjnego $\gamma=0 ; 0.01 ; 0.1$ oraz 1. Dokładność wyznaczenia rozkładu temperatury - eps $=5 \cdot 10^{-5}$.



Rys. 2. Obszar $\Omega$ - pierścień eliptyczny z przesuniętymi brzegami

Fig. 2. Domain $\Omega$ - the elliptical ring with shifted boundaries

Zbadany został wpływ błędu losowego $\delta$ oraz parametru $\gamma$ na czas obliczeń opisanym w pracy algorytmem iteracyjnym. Z przedstawionych $w$ tablicy 1 i na rys. 3 danych wynika, że wraz ze wzrostem parametru $\gamma$ skraca się czas obliczeń.

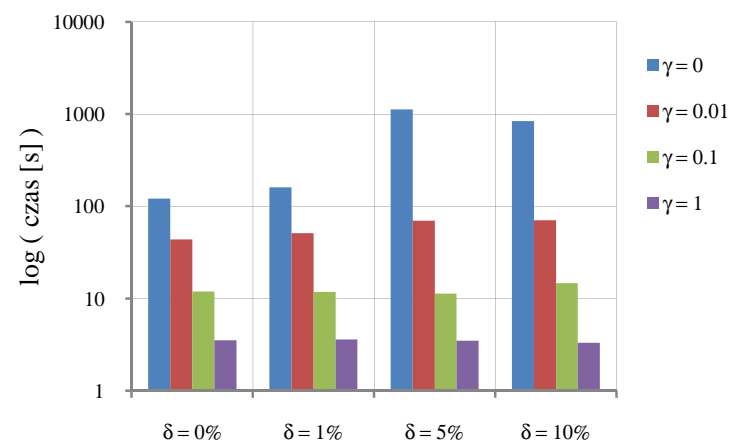

Rys. 3. Porównanie czasów obliczeń dla różnych wartości parametru $\gamma$ i błędów losowych warunków brzegowych $\delta$

Fig. 3. Comparison of times of calculations for different values of parameter and random errors of boundary conditions $\delta$ 
Tablica 1. Porównanie czasu obliczeń $t[s]$ dla różnych wartości parametru $\gamma$ błędu zaburzenia warunków brzegowych $\delta$

Table 1. Comparison of times of calculations $t$ [s] for different values of $\gamma$ parameter and the disturbance error of the boundary conditions $\delta$

\begin{tabular}{|l|r|r|r|r|}
\hline$t[s]$ & $\delta=0 \%$ & $\delta=1 \%$ & $\delta=5 \%$ & $\delta=10 \%$ \\
\hline$\gamma=0$ & 121 & 160 & 1119 & 834 \\
\hline$\gamma=0.01$ & 44 & 51 & 70 & 70 \\
\hline$\gamma=0.1$ & 12 & 12 & 11 & 15 \\
\hline$\gamma=1$ & 4 & 4 & 4 & 4 \\
\hline
\end{tabular}

Do oceny jakości rozwiązania zostały wprowadzone normy:

- $N_{T}$ - norma względna będąca miarą odległości rozkładu temperatury na brzegach zewnętrznym $N_{T z}=N_{T}\left(\Gamma_{z}\right)$ i wewnętrznym $N_{T w}=N_{T}\left(\Gamma_{w}\right)$ od rozwiązania analitycznego $T_{a}(20)$

$$
N_{T}(\Gamma)=\frac{\int_{\Gamma}\left(T-T_{a}\right)^{2} d s}{\int_{\Gamma} T_{a}^{2} d s} \cdot 100[\%]
$$

- $N_{T s}$ - norma względna będąca miarą odległości pochodnej stycznej temperatury na brzegach zewnętrznym $N_{T s z}=N_{T s}\left(\Gamma_{z}\right)$ i wewnętrznym $N_{T s w}=N_{T s}$ $\left(\Gamma_{w}\right)$ od rozwiązania analitycznego $T_{a}(20)$ (miara oscylacji temperatury na brzegach pierścienia)

$$
N_{T s}(\Gamma)=\frac{\int_{\Gamma}\left(\frac{d T}{d s}-\frac{d T_{a}}{d s}\right)^{2} d s}{\int_{\Gamma}\left(\frac{d T_{a}}{d s}\right)^{2} d s} \cdot 100[\%]
$$

- $N_{T n}$ - norma względna będąca miarą odległości pochodnej normalnej temperatury na brzegach zewnętrznym $N_{T n z}=N_{T n}\left(\Gamma_{z}\right)$ i wewnętrznym $N_{T n w}=$ $N_{T s}\left(\Gamma_{w}\right)$ od rozwiązania analitycznego $T_{a}(20)$

$$
N_{T n}(\Gamma)=\frac{\int_{\Gamma}\left(\frac{d T}{d n}-\frac{d T_{a}}{d n}\right)^{2} d s}{\int_{\Gamma}\left(\frac{d T_{a}}{d n}\right)^{2} d s} \cdot 100[\%]
$$


Wartości tych norm dla różnych wartości parametrów $\delta$ i $\gamma$ przedstawiono na rys. $4,5,6$.dla małych wartości parametru $\gamma$.

Dla $\gamma=0$ błąd wyznaczenia rozwiązania na brzegu wewnętrznym wg norm (21), (22), (23) zależy od wartości błędu losowego $\delta$. Wpływ ten wraz ze wzrostem parametru $\gamma$ maleje. Charakterystyczne dla rozwiązania zagadnienia odwrotnego są oscylacje rozwiązania mierzone za pomocą normy (22). Z wyników obliczeń przedstawionych na rys. 5 widać, że funkcjonał postaci (2) silnie tłumi oscylacje rozwiązania, zmniejsza wpływ błędu losowego $\delta$ na rozwiązanie, ale powoduje również obniżenie dokładności rozwiązania dla $\delta=0$.
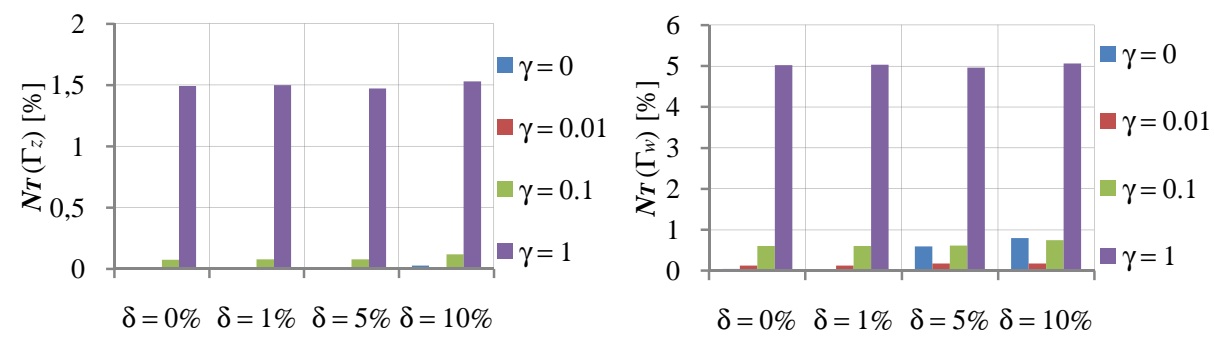

Rys. 4. Porównanie wartości norm NTna brzegu zewnętrznym (z lewej) i wewnętrznym (z prawej) dla różnych wartości parametru $\gamma$ i błędów losowych warunków brzegowych $\delta$

Fig. 4. Comparison of values of norms $N_{T}$ on the outer boundary (left) and on the inner one (right) for different values of $\gamma$ parameter and for random errors of boundary conditions $\delta$



$\delta=0 \% \quad \delta=1 \% \quad \delta=5 \% \quad \delta=10 \%$

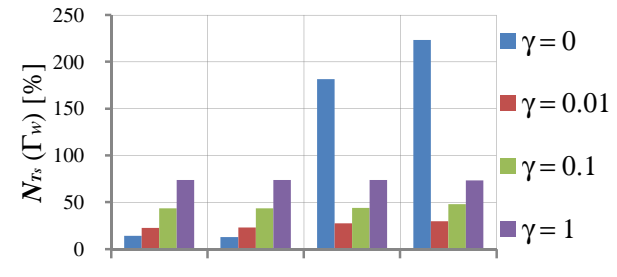

$\delta=0 \% \quad \delta=1 \% \quad \delta=5 \% \quad \delta=10 \%$

Rys. 5. Porównanie wartości norm NTs na brzegu zewnętrznym (z lewej) i wewnętrznym (z prawej) dla różnych wartości parametru $\gamma$ i błędów losowych warunków brzegowych $\delta$

Fig. 5. Comparison of values of norms $N_{T s}$ on the outer boundary (left) and on the inner one (right) for different values of $\gamma$ parameter and for random errors of boundary conditions $\delta$ 

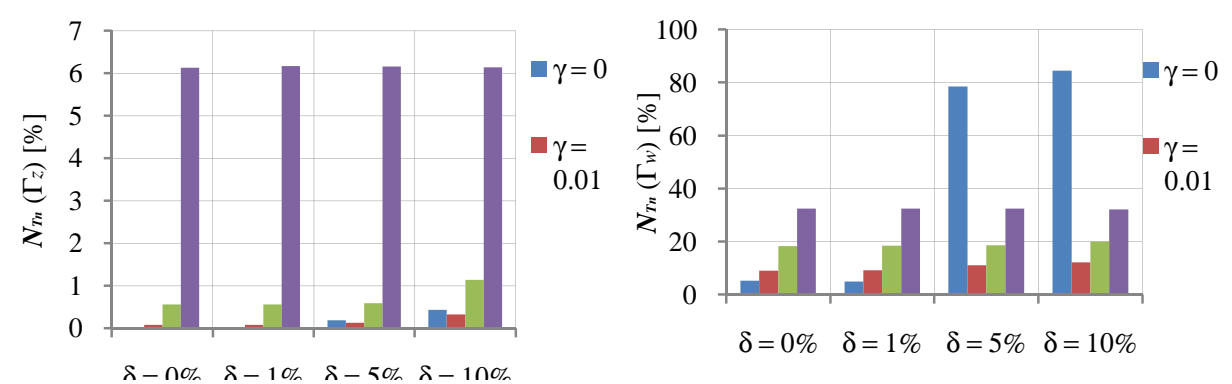

Rys. 6. Porównanie wartości norm $N T n$ na brzegu zewnętrznym (z lewej) i wewnętrznym (z prawej) dla różnych wartości parametru $\gamma$ i błędów losowych warunków brzegowych $\delta$

Fig. 6. Comparison of values of norms $N T_{n}$ on the outer boundary (left) and on the inner one (right) for different values of $\gamma$ parameter and for random errors of boundary conditions $\delta$

\section{Podsumowanie}

W pracy przedstawiony został algorytm iteracyjny rozwiązujący zagadnienia odwrotne przewodnictwa ciepła w obszarach wielospójnych. Wybrany do optymalizacji rozwiązania zagadnienia odwrotnego testowego funkcjonał (2) zmniejszył oscylacje rozwiązania, skrócił czas obliczeń, ale obniżył dokładność rozwiązania dla współczynnika przejmowania ciepła $\alpha$ na brzegu zewnętrznym obszaru wielospójnego wyznaczonego ze wzoru analitycznego. Zmniejszony został wpływ błędu losowego warunków brzegowych na rozwiązanie zagadnienia odwrotnego.

Wyniki obliczeń przedstawione w pracy wskazują na możliwość stosowania tego algorytmu iteracyjnego dla zagadnień odwrotnych związanych z chłodzeniem łopatek turbin gazowych. Celem dalszych badań pozostaje kwestia optymalnego doboru parametru $\gamma$.

\section{Literatura}

[1] Alifanov O.M.: Inverse Problems, Moscow 1988.

[2] Beck J.V., Blackwell B., Clair C.R.: Inverse heat conduction Ill-Posed problems, New York 1985.

[3] Frąckowiak A., Ciałkowski M., Wróblewska A.: Iterative algorithms for solving inverse problems of heat conduction in multiply connected domains, Int. J. Heat Mass Transfer, 55 (2012) 744-751.

[4] Frąckowiak A., v.Wolfersdorf J., Ciałkowski M.: Application of inverse problem of the Poisson equation in the cooling process of a gas-turbine blade, Int. J. Heat Mass Transfer, 54 (2011) 1236-1243.

[5] Hadamard J.: Sur les problèmes aux dérivéespartielles et leur signification physique. Princeton University Bulletin, pp. 49-52, 1902. 
[6] Hylton L.D., Mihelc M.S., Turner E.R., Nealy D.A., York R.E.: Analytical and experimental evaluation of the heat transfer distribution over the surfaces of turbine vanes, NASA CR-168015 DDA EDR 11209, 1983.

[7] Louis A.K.: Inverse und schlechtgestellte Probleme, Teubner Studienbucher Mathematik, Stuttgart 1989.

[8] Tikhonov A.N., Arsenin V.Y.: Solutions of Ill-posed problems, Winston and Sons, Washington 1977.

\title{
ALGORITHM FOR ITERATIVE SOLVING THE INVERSE HEAT CONDUCTION PROBLEMS WITH MINIMIZATION OF TEMPERATURE OSCILLATIONS
}

\begin{abstract}
S u m m a r y
In this paper, the inverse problem for the steady-state temperature field in the multiplyconnected domain was solved, which is of great importance from technical point of view and concerns the problem of cooling the gas turbine blades. Test inverse problem for domain of the elliptical ring with the known temperature distribution and the heat transfer coefficient on the outer boundary of the domain was solved. On this basis the distributions of temperature and heat flux density on the inner boundary of the ring were determined. The optimization functional of the solution of the inverse problem comprises a term related to the temperature gradient in the whole domain. Calculations were made for the known distribution of the heat transfer coefficient on the outer boundary of the domain disturbed by random error equal of $0,1,5$ and $10 \%$. The influence of the temperature gradient on time and the accuracy of calculations was examined. Taking into account the temperature gradient in the functional, which is minimized in the calculation process, reduced the time of calculations and decreased oscillations of the temperature as well as heat flux distributions on the inner boundary of the multiply-connected domain.
\end{abstract}

Keywords: gas turbine, inverse problems, Cauchy problem

DOI: $10.7862 / \mathrm{rm} .2014 .37$

Otrzymano/received: 25.05 .2014

Zaakceptowano/accepted: 28.06.2014 